\title{
Wallowing in Buffalo and summer management
}

Compiled By: Dr.Champak Bhakat,PS, ERS- NDRI, Kalyani

\section{Wallowing behavior in buffalo:}

Wallowing has two purposes; the most obvious is that of cooling, the other is protection from insects. Wallowing during day time is done during the hottest hours. Wallowing during night time is instead a way for the animal to protect itself from insects. The buffalo has few sweat glands and a dark skin which makes it difficult for them to maintain their body temperature in hot and humid environments. Wallowing is a very important way for the buffaloes to maintain their body temperature. When buffaloes enter the water, they defecate and/or urinate. This seems to be a way to mark their wallow. Wallowing behavior is a learnt behavior. An animal that has not wallowed from birth with other animals will not do so on its own. Teaching such an animal to wallow is almost impossible for humans. The buffalo has to learn it from other buffaloes, even so, the adult buffalo will be very suspicious and may not wallow by its own choice. If no water or mud hole is available, the buffaloes behave more like cattle. They will seek shade and graze more during the cool hours and less during the hot hours. Amongst different environmental conditions, it is the hot weather that compromises the productive and reproductive performance of livestock species. The plains, coast-line and foot-hill regions of the Indian subcontinent, home to over $90 \%$ of the worlds' buffaloes, experience varied and extreme weather conditions, with temperatures reaching up to $48^{\circ} \mathrm{C}$ in summers and as low as minus $2^{\circ} \mathrm{C}$ in winters. The presence of large buffalo population in such diverse climatic conditions indicates that buffaloes are well-adapted to such climatic extremes. Yet, it is generally believed that buffaloes are sensitive to heat stress, owing to:

Thick black skin color that absorbs more solar radiations, which are high in the region.

$\square$ Sparse hair coat, considered inadequate to insulate the buffalo from high temperatures.

Buffalo skin has fewer (almost $1 / 6^{\text {th }}$ ) sweat glands in the skin than Zebu, situated deep in the skin, compromising heat dissipation through evaporative heat loss.

These peculiar morphological and anatomical characteristics make buffalo poor thermoregulator, thereby tending to increase the internal body heat, which in turn, takes its toll on food intake, productivity as well as reproductive performance of the animal. Thus it is no surprise that there is a scarcity of milk in this region during summer months, while most of the calving are concentrated during rainy 
and winter months of the year.

Inspite of these facts, which tend to suggest susceptibility of buffalo to heat stress due to its unique thermoregulatory mechanisms, the presence of large population of buffaloes in such harsh hot climates could possibly be due to some of the special anatomical, behavioral and morphological features of the skin in this species. Such features include the characteristic black skin that contains numerous melanin granules, which provide protection against UV rays component of sun light. UV rays are abnormally high in the typical hot climates of the tropics. Further, buffalo dermis has well-developed sebaceous glands and their oily secretions make skin slippery for water and mud. This possibly acts as a defense against harmful ingredients present in mud and water while wallowing. The oil secretions from skin make it more lustrous during summer to reflect solar radiations more effectively.

\section{Common terms associated with heat stress}

$\varnothing$ Heat wave: Long period of excessively hot climate.

$\varnothing$ Heat Cramps: Muscular pain and spasm due to heavy exertion in hot climate.

$\varnothing$ Heat Exhaustion: Excessive loss of body fluids (usually through sweat) leading to fatigue.

$\varnothing$ Heat-stroke / Sun-stroke: Break-down in thermoregulatory system of the body leading to increased internal temperature with no sweating and death, if not immediately treated.

\section{Adaptive changes in response to heat}

In response to heat-stress, numerous physiologic changes occur in the animal system including altered acid-base chemistry and endocrine glands activity, in response to compromised thermoregulation as well as reduced nutrient intake. Nevertheless, many changes occur as a result of stress in the animal.

Neurons, which are temperature sensitive, are located throughout the animal's body and send information to the hypothalamus, which invokes numerous physiological, anatomical or behavioural changes in an attempt to maintain heat balance. During heat stress, buffalo exhibits reduced feed intake, decreased activity, seeks shady and airy places, increases respiratory rate, peripheral blood flow and sweating. Table 1 lists different physiological adjustments in the animal's body in response to heat stress. 
Table 1. Physiological effects of heat on buffalo

\begin{tabular}{|c|c|}
\hline Effect & Implications \\
\hline $\begin{array}{l}\text { Hemodynamic } \\
\text { effects }\end{array}$ & $\begin{array}{l}\text { Increased blood flow to skin and peripheral tissue } \\
\text { resulting in:- } \\
-\quad \text { increased hydrostatic pressure } \\
-\quad \text { increased capillary permeability } \\
-\quad \text { leucocytic and antibody infiltration } \\
-\quad \text { analgesia }\end{array}$ \\
\hline $\begin{array}{l}\text { Neuromuscular } \\
\text { effects }\end{array}$ & $\begin{array}{l}\text { Increased nerve conduction velocity, decreased firing } \\
\text { rate of motor neurons resulting in muscle relaxation and } \\
\text { increased pain threshold }\end{array}$ \\
\hline Metabolic effects & $\begin{array}{l}\text { Stimulation of hypothalamus resulting in increased } \\
\text { metabolic rate, oxygen uptake and accelerated healing }\end{array}$ \\
\hline $\begin{array}{l}\text { Soft tissue } \\
\text { extensibility }\end{array}$ & $\begin{array}{ll}\text { Increased collagen extensibility for maintaining greater } \\
\text { length after stretching for: } \\
-\quad \text { decreased elasticity } \\
-\quad \text { less force required to increase length } \\
- & \text { decreased risk of tissue tearing }\end{array}$ \\
\hline
\end{tabular}

These responses have deleterious effect on both productive and reproductive status of the animal. Fig. 1 illustrates different physiological adjustments in body of a buffalo in response to heat stress. 


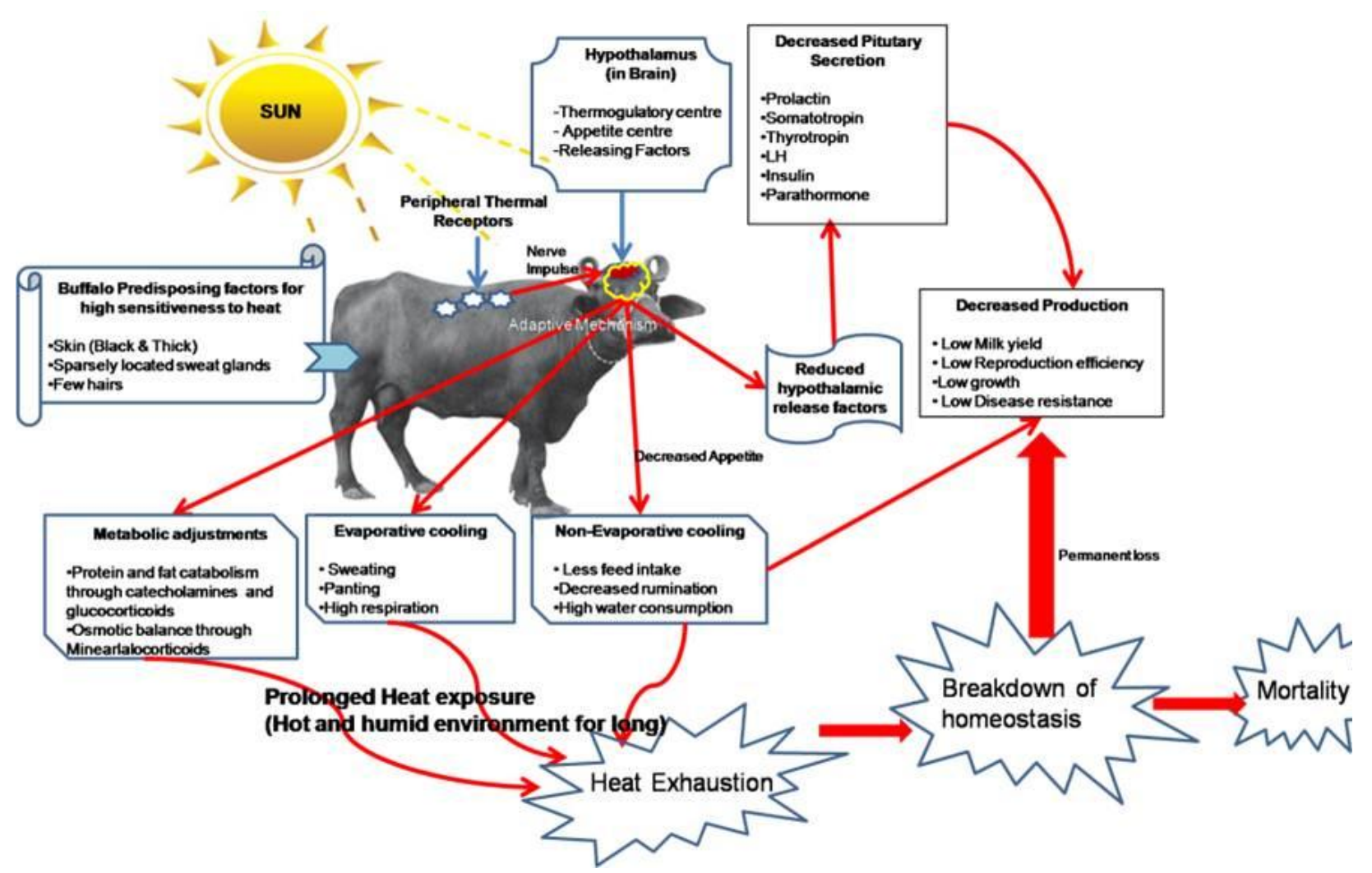

Fig. 1 Physiological mechanisms during heat stress in buffalo

The negative effect of heat stress on milk production is due to the decreased nutrient intake and decreased nutrient uptake by the portal drained viscera of the buffalo. Blood flow shift to the peripheral tissues for cooling purpose alters the nutrient metabolism and contributes to lower milk yield during hot weather. Hormonal alterations associated with heat stress include decline in plasma somatotropin and thyroxine concentrations in an attempt to reduce metabolic heat and consequently, milk production. Heat-stressed buffalo exhibits altered blood acid-base chemistry as a result of the shift in thermoregulation from conduction, convection and radiation mediated heat-loss to evaporative cooling. Heat-stressed animal has elevated rectal temperature and respiration rate accompanied with diurnal variations in blood $\mathrm{pH}$ and bicarbonate values. Wide swings in acid-base chemistry, from alkalosis to compensated acidosis, result in metabolic acidosis during the cooler evening hours. Reduced concentrations of blood bicarbonate compromise the buffering capability associated with the bicarbonate system, which may be critical during summer. During hot season, the dry matter intake of buffalo is decreased and the ratio of forage to concentrate intake is also decreased. In other words, the decline in milk yield at higher temperature is more marked in a buffalo that produces more milk. There is a significant relationship between the level of milk yield and the decline in milk yield associated with increase in daily mean environmental temperature. 


\section{How to recognize heat stress}

Changes in consciousness: Rapid and weak pulse, rapid but shallow breathing;

Abnormal vital parameters: Elevated heart rate, respiration rate, rectal temperature;

Unusual salivation: Capillary refill is very fast

In case of heat stroke - very high body temperature - sometimes as high as $106-108^{\circ} \mathrm{F}$.

Heat stroke is life-threatening, so immediate veterinary attention is a must while moving the animal to cooler place, giving bath with cold water or wrapping in wet sheets and providing fan.

Signs of heat exhaustion: Dizziness / unconsciousness; Skin becomes dull and may be cold too.

\section{Management of heat stress:}

\section{Modification of the micro-environment / Use of cooling system :}

Careful management is important to alleviate heat stress and maintain high production levels in lactating buffaloes under hot environmental conditions. Good management practices include modification of the surrounding environment to reduce the impact of environment and at the same time promote heat loss from the animal. Combating heat stress in buffaloes can be through various management practices such as provision of shade, increasing air movement and repeatedly wetting the animal with cold water for greater evaporative cooling.

\section{Shade:}

Simple shade is the basic method of protecting animals from direct solar radiation in day-time during summer. The most effective source of shade is the trees and plants. They provide not only protection from sunlight, but also create a cooling effect through the evaporation of moisture from their leaves. Shade has a beneficial effect on the physiological response of buffaloes to heat as the body temperature, heart rate and respiration rate all decreased when shade is provided during summer. These practices shall reduce the impact of solar heat while maximizing heat dissipation from the animal.

\section{Air movement:}

Air movement becomes more important during hot-humid climate for providing cooling and comfort to the animal. Apart from shifting animal to shaded airy place, fans or dairy fans and different types of coolers can also be installed for 
making the place airy. Air movement increases the rate of heat loss from animal's body surface, only as long as the air temperature is lower than the animal's skin temperature.

\section{Evaporative Cooling:}

For this, various cooling systems have been developed such as holding-pen cooling, exit-lane cooling, and free-stall cooling. These systems are applicable for the animals maintained in covered pucca sheds. An evaporative system which uses water mist with fan is more effective and economises water use in comparison to repeatedly bathing the animals. Some farmers prefer sprinklers or mister, installed on the roof or at various places in the barn. The use of a combination of evaporation and air movement such as 'mist fans' are more effective, economical and useful than fans and wetting alone. Water sprinklers generate a large volume of waste water.

\section{Feeding strategies in hot environment}

There are several key areas of nutritional management which should be considered during hot weather. These include special formulation to account for reduced dry matter intake with corresponding greater availability of key nutrients and to compensate for dietary heat increment while avoiding nutrient excesses. The energy requirements of lactating buffaloes also increase under high temperature conditions, but this increase is apparently caused primarily by the increase in metabolic energy.

\section{Water intake:}

Water is arguably the most important nutrient for buffalo during hot climate. Water intake is closely related to dry matter intake and milk yield, but regardless of the rate of increase, it is important that abundant water must be available at all times under hot conditions. Hot weather, declining dry matter intake and high lactation demand requires increased dietary mineral concentration. The primary cat-ion in bovine sweat is potassium. Sharp increases in the secretion of potassium through sweat occur during hot climatic conditions Alterations in mineral metabolism also affect the electrolyte status of buffalo during hot weather. So it important to supplement minerals during hot climate.

\section{Night Grazing:}

Buffaloes kept in a shed maintain rapid heartbeat during the night. However, when the animals are allowed out into a pasture at night, these physiological responses decrease immediately. This is the result, both of a reduction in 
radiation heat from the surrounding buffaloes, as well as increased heat loss from the animal itself.

\section{Feeding High-Energy Diets:}

Low-fiber, high fermentable carbohydrate diets lower dietary heat increment compared to high fibre diets. Although the metabolic energy of dairy buffaloes increases in a hot environment, heat stress depresses feed intake. For this reason, it is important to increase the energy content of the diet of dairy buffaloes, in order to maintain their energy intake under hot conditions. The heat increment, which is an internal heat stressor in hot environments, is lower in highly metabolizable diets. So it is imperative to use fatty feeds, or calcium salts of fatty acids, as the means of improving energy supply for buffaloes in summer. Buffaloes fed on such diets have higher milk yield, and a lower body temperature and respiration rate.

\section{Feeding by-Pass Protein:}

Dietary protein degradability is also critical under heat stress conditions. It is well known that excessive protein intake increases heat production and decreases reproductive performance. However, the protein requirement of buffalo increases and dry matter intake decreases in a hot environment, consequently, the protein supplied to lactating buffaloes during summer is not always sufficient. By using fish meal, which is a by-pass protein, the milk yield and protein content of buffalo milk increases but the ruminal ammonia production decreases.

\section{Genetic selection}

There are many aspects of genetics that influence the animal's response and endurance to heat stress. Accordingly, wide variations in the same are evidenced among different breeds of livestock. The maintenance of body temperature is heritable through characteristics like coat structure and color, sweating competence, low tissue resistance etc. So selection of animals through specific genetic markers for heat tolerance will help to address the problem of heat stress in buffaloes by identifying the heat stress tolerant animals.

\section{Other management practices for breeding buffaloes:}

- Selective breeding needs to be strengthened for genetic improvement in buffalo breeds, using genetically superior bulls at existing organized farms. It is expected that $1-1.5 \%$ improvement in milk production per annum will be achieved in herds at organized farms and 8-10\% in farmers' herds.

- In certain parts of states like Gujarat, Rajasthan and Karnataka, Surti is the 
breed of choice. Murrah is generally the breed of choice in Haryana, parts of Punjab and Western U.P., while in other parts of Punjab Nili Ravi has a sizable population and also needs to be improved.

- Genetic improvement for higher milk production, reduced age at maturity, reduced service period, dry period and calving interval will lead to higher economic returns.

- The production potential of low producing non-descript buffaloes in low to medium input production systems, in areas where feed resources and marketing facilities are moderately available, can also be increased rapidly by using sires of improved breeds like Murrah, Surti and Mehsana.

- Surti is recommended for Karnataka, Kerala, parts of Gujarat and Rajasthan; Nili Ravi for a few parts of Punjab; Murrah for Haryana, parts of western Uttar Pradesh and Punjab. In other parts of the country where sufficient feed resources are available, Murrah is recommended for grading up of nondescript buffaloes.

- This programme is also expected to increase meat production. Through use of superior breeds over four to five generations, low producing non-descript buffaloes can be replaced with animals that are relatively high producing for both milk and meat.

In hot-humid climates, although buffalo attempts to acclimatize through physiological changes including cutting down on feed intake and heat production, but this does not come without sacrificing part of its productivity. In order to prevent this economic loss to the farmer, there is need to understand and effectively combat heat stress by minimizing its impact on animal body and its productivity. Over generations, continued genetic selection for improved dry matter intake and milk yield under adverse climates, will pave the way for producing buffaloes that are better equipped for heat tolerance. In the short term, there is no substitute to good management practices to ameliorate heat stress, which include nutritional management and infrastructure facilities for providing comfort to the animal in the event of harsh hot climate. There is little doubt that a buffalo shall repay the investment in due course of time through continued high milk productivity and maintaining good reproductive efficiency for higher life-time productivity. 